\title{
The methanogenic archaea characteristics and efficacy of aerobic waste sludge in the start-up of anaerobic hybrid reactors treating cassava wastewater
}

\author{
Pratin Kullavanijaya $^{1^{+}}$, Pattama Thongduang ${ }^{1}$, Nimaradee Boonapatcharoen ${ }^{1}$, \\ Chalisa Veesommai Sillberg ${ }^{2}$ \\ ${ }^{1}$ King Mongkut's University of Technology Thonburi, Pilot Plant Development and Training Institute, Excellent Center of Waste Utilization and \\ Management, Bangkok 10150, Thailand \\ ${ }^{2}$ Kasetsart University, Faculty of Environment, Department of Environmental Science, Bangkok 10900, Thailand
}

\begin{abstract}
Inoculum is a crucial factor influencing the success of an anaerobic digester start-up. This study evaluated the efficacy of aerobic waste activated sludge (WAS) to start-up anaerobic hybrid reactors (AHR) treating cassava wastewater. The start-up performance and stability of five 6.2 L AHRs inoculated differently by WAS (AHR1) and WAS co-inoculated with pig manure (AHR2), cow dung (AHR3), chicken manure (AHR4), and anaerobic pond sludge (AHR5) were investigated. The results depicted the potential of WAS as starter seed for AHR's start-up. This sludge contained methanogenic populations, mainly Methanomicrobials, Methanosarcinales, and Thermoplasmatales, for $1.5 \times 10^{7} \mathrm{MPN} / \mathrm{g}$ VS compared to $4.0 \times 10^{3}-6.0$ $\times 10^{7} \mathrm{MPN} / \mathrm{g}$ VS in manures and anaerobic sludge. Co-inoculation of WAS with cow dung (AHR3) and anaerobic sludge (AHR5) promoted a rapid start-up, achieved $4.0 \mathrm{~kg} \mathrm{COD} / \mathrm{m}^{3} . \mathrm{d}$ within $1.5-1.7$ months, while about 2.5-3.3 months needed for the others. A satisfying performance, stability, microbial development and activity, depicted as high $\mathrm{COD}$ removal $\left(\mathrm{COD}_{\mathrm{rem}}\right)$ efficiency and methane productivity, were achieved in all digesters. About 0.32 and $0.21 \mathrm{~m}^{3} / \mathrm{kg} \mathrm{COD}$ rem for biogas and methane yielded in AHR1, whereas $0.41-0.49 \mathrm{~m}^{3}-\mathrm{biogas} / \mathrm{kg}$ COD $\mathrm{rem}$ and $0.25-0.32$ $\mathrm{m}^{3}-\mathrm{CH}_{4} / \mathrm{kg} \mathrm{COD}_{\text {rem }}$ obtained in other reactors. This finding confirmed that inoculum's quality is critical for productive gas productivity and system stability maintenance.
\end{abstract}

Keywords: Biogas, Bio-sludge, Co-culture, Seed, Starter, Waste activated sludge

\section{Introduction}

Anaerobic digestion is an effective solution in treating and stabilizing organic constituent wastes and wastewaters [1]. This process gains many recognitions benefit over aerobic-based digestion, mainly low-energy consumption, less bio-sludge generation, and simultaneous production of methane gas, use potentially as fuel. Nowadays, many types of anaerobic digester configuration are operated worldwide for various feedstocks [2]. Anaerobic digestion employs significantly diversified microorganisms, principally methanogens and non-methanogens, to degrade organic matter under an oxygen-free environment through four significant steps: hydrolysis, acidogenesis, acetogenesis, and methanogenesis [3]. In general, the methanogenesis of the anaerobic process is a limiting step due to the slow-growing rate of methanogens [4]. This step is a consequent constrain to the start-up of the digester. The quality of an initial inoculum is an essential factor influencing the success of start-up operation and long-term stability.

To start up an anaerobic reactor, bio-sludge from a digester operating for similar background history and wastewater type is preferred. This sludge is expected to adapt well to a new digestion environment and significantly utilize wastewater substances. It was found that seed inoculum played a crucial role in various biodegradation due to a diversification of microbial consortia [4-6]. The importance of seed inoculum on the digester's performance and stability were stated previously for different types of substrates
This is an Open Access article distributed under the terms of the Creative Commons Attribution Non-Commercial License (http://creativecommons.org/licenses/by-nc/3.0/) which permits unrestricted non-commercial use, distribution, and reproduction in any medium, provided the original work is properly cited.

Copyright (C) 2022 Korean Society of Environmental Engineers
Received March 30, 2021 Accepted June 16, 2021

${ }^{\dagger}$ Corresponding author

E-mail: pratin@pdti.kmutt.ac.th

Tel: +66 24707526 Fax: +66 24523455

ORCID: 0000-0003-1091-6824 
digestion, i.e. food waste, sewage sludge, crops, microalgae, and manure [7-10]. To shorten the digester's start-up time, a large amount of seed inoculum is commonly required. In this case, inoculum's quality is also an essential factor governing start-up efficacy and time consumption. Optimization of seed inoculation either by dosage increment and activity enhancement is a possible strategy. The optimum is a tradeoff between transportation cost and start-up time when inoculated by the different concentrations of seed sludge. Hence, an alternative source of inoculum that contains a surplus supply capacity, an excellent microbial community for seeding initially either by mono-, co- or mixed-cultures is necessary. The common inoculum sources are anaerobic sludge and ruminal manures, i.e. dairy cow, cattle or buffalo manure [5]. Another alternative source, i.e. swine manure [6], turf [11], organic fraction of municipal solid waste [12], and zebra dung [13], were also studied.

In Thailand, anaerobic technology had been introduced for several decades $[14,15]$. However, the implementations are diminished in feedstock type and plant scale, mainly small to medium scale plants for animal manures, i.e. cow and pig manure. The other large-scale plants are for tapioca wastewater and palm oil mill effluent treatment [14]. This low diversity and limited numbers of operating digester encourage less quantity of good quality sludge to start up new biogas plant subsequently. Therefore, the start-up stage of these plants experienced a long period practically and much attention to accomplish in many cases [16]. As stated previously, cow dung and anaerobic sludge are a common source of inoculum. However, the use of these inoculums also faces several constraints, such as collection and transportation. For example, it is not easy to collect the cattle's manure, usually free-range animal husbandry. They grow in the field, not in the cage. However, the situation is better for a dairy cow that is stabling. Due to the number of biogas plant in the nearby area of the start-up is rarely, the transportation cost of starter seed, from the original to the new site, is promoted. The use of anaerobic pond's sludge is usually costly by low solid concentrations contained. Moreover, the supply capacity of bio-sludge from anaerobic digester is low for many reasons, i.e. less bio-sludge generated naturally, small to medium scale digester operated mainly, and fully commercialized operations with high production cost.

The present study aims to evaluate the efficacy of aerobic waste activated sludge (WAS) as a starter seed for anaerobic digester start-up. This bio-sludge is considered as a potential inoculum source for two main reasons: a surplus production amounts of WAS found in almost every city [17, 18], and the characteristic of dewatered WAS benefits to transport from place to plant. Although several studies had been reported about WAS utilization, different applications were found. The primary studies focused on the utilization of WAS as feedstock. Some studies verified the existence of some specific microbes, i.e. archaea (Arc) or methanogens, nitrifying bacteria, to use proposes explicitly, i.e. to use as inoculum for toxicity test. Several studies reported on Arc in WAS, i.e. Wu et al. [19] found an Arc population of $1.5 \times 10^{8} \mathrm{MPN} / \mathrm{g}$ of VS in aeration tank's sludge of the sewage treatment plant, while about $4.1 \times 10^{5} \mathrm{MPN} / \mathrm{g}$ VS of acetolactic methanogens also reported by William and Brown [20]. A similar finding was stated in others tested samples, except one fully aerated by pure oxygen [21]. To evaluate sludge's performance, the experiments were conducted mainly in batch digestion and laboratory-scale conditions to investigate its degradability for some specific substrates, i.e. glucose, acetic acid (HAr), and propionic acid (HPr) [22]. The gradual operation strategy was suggested to optimize feeding for synthetic-based wastewater substitution by the real one [23]. Rarely implementation found in a continuous operation with industrial wastewater digestion. Therefore, to practical implantation of waste bio-sludge herein WAS from the domestic wastewater treatment plant to start-up anaerobic hybrid reactor (AHR), experiments were conducted in five identical AHRs. The mono-and co-inoculation strategy of WAS with other source was evaluated. The methanogenic Arc populations were characterized, and digester's performance, stability, and microbial biomass development were mentioned.

\section{Materials and Methods}

\subsection{Anaerobic Hybrid Reactor}

The start-up experiment was conducted in five identical anaerobic hybrid reactors (AHR), each with 6.2 L-working volume, operated at the ambient temperature ranged between $24.4-30.6^{\circ} \mathrm{C}$. The hybrid reactor consists of two different characteristics of microbes by hybridizing the merit of attached growth biomass in the upper half and the suspended growth biomass in the lower left part of the tank. The nylon fibre was used as the supporting material installed in the attached zone [24]. These AHRs were made of transparent acrylic in a cylindrical shape with $9.6 \mathrm{~cm}$ diameter and $86.5 \mathrm{~cm}$ high. Influent wastewater was fed continuously in an upward direction using a peristaltic pump. Liquid and gas sampling ports were provided in each AHR, as well as a gas counter device was also connected individually to measure the produced biogas.

\subsection{Wastewater and Inoculum}

Cassava starch production is a primary food industry in Thailand. This process generates not only a starch product, but it has been estimated that about $13-20 \mathrm{~m}^{3}$ of wastewater also produced each ton of starch $[15,25]$. In this study, wastewater from cassava starch processing, hereafter called cassava wastewater, was selected and used as feedstock for the AHRs start-up. This raw cassava wastewater was collected from a factory located in the East to use throughout the experiment. In preparation, the concentration of feed wastewater was ranged between 6.8-16.0 g of the total chemical oxygen demand per litre (g TCOD/L). At the initial start-up stage or organic loading rate (OLR) of $0.5 \mathrm{~kg} \mathrm{COD} / \mathrm{m}^{3} . \mathrm{d}$, COD concentration of influent wastewater was diluted to a low range of $6.8 \mathrm{~g} / \mathrm{L}$, the concentration of about 13.0-16.0 g TCOD/L was then applied. In practice, raw wastewater was diluted with tap water partially for $10-30 \%$ by volume to a particular concentration. A buffering capacity was adjusted by adding $\mathrm{NaHCO}_{3}$ about $1.5 \mathrm{~g} / \mathrm{L}$. This wastewater was kept at $4^{\circ} \mathrm{C}$ and fed to each reactor.

For inoculum, two types of sludge and three types of manure were selected and applied as a starter seed: aerobic waste activated sludge (WAS), pig manure (PM), cow dung (CD), chicken manure (CM), and anaerobic sludge (AN). CD and AN were a useful source commonly use to starter-up the digester, while others were alternatively. The fresh dewatered WAS was collected from the 
sludge dewatering via the belt-press unit of the metropolitan domestic wastewater treatment plant. Fresh PM, CD, and CM were collected from a small farm located in Ratchaburi province, while AN was obtained from the anaerobic pond of the same cassava starch processing factory. These inoculums were screened to eliminate large and inert fractions using a coarse screener. In each AHR, the initial concentration inoculation was controlled at $10.0 \mathrm{~g} \mathrm{VS} / \mathrm{L}$. In the case of co-inoculation, each with $5.0 \mathrm{~g}$ VS/L was used. Five AHRs named accordingly to the inoculation as AHR1-WAS for mono WAS inoculation, AHR2-WAS-PM for co-inoculation of WAS and PM, AHR3-WAS-CD for co-inoculation of WAS and CD, AHR4-WAS-CM for co-inoculation of WAS and CM, and AHR5-WAS-AN for co-inoculation of WAS and AN, respectively. The chemical characteristics of the raw wastewater and applied inoculums are summarized in Table 1.

\subsection{Start-up Procedure}

After the initial seeding, each reactor was fed separately by cassava wastewater. The organic loading rate (OLR) was stepwise increased by $0.5 \mathrm{~kg} \mathrm{COD} / \mathrm{m}^{3}$.d, from 0.5 to $4.0 \mathrm{~kg} \mathrm{COD} / \mathrm{m}^{3}$.d. This targeted OLR is a practical loading of cassava wastewater feed digester [14, 15]. The increase of OLR was done by decreasing the hydraulic retention time (HRT) from $13.0 \mathrm{~d}$ to $4.0 \mathrm{~d}$, respectively. At the early stage of start-up or OLR of 0.5-1.0 $\mathrm{kg} \mathrm{COD} / \mathrm{m}^{3} . \mathrm{d}$, the volume of daily feeding wastewater was low. Thus, a slug feeding mode with an internal recirculation was applied. Afterwards, the continuous feeding was operated for 1.0-4.0 $\mathrm{kg} \mathrm{COD} / \mathrm{m}^{3}$.d. The effluent and biogas samples were collected regularly for further analysis to monitor each reactor's performance and stability. In comparison, the same targeted OLR of $4.0 \mathrm{~kg} \mathrm{COD} / \mathrm{m}^{3} . \mathrm{d}$ was a basis.

\subsection{Sample and Data Analysis}

The overall performance and stability of digesters were regularly monitored via mainly chemical parameters. The effluent samples collected daily for analysis of such parameters as $\mathrm{pH}$, alkalinity (Alk), volatile fatty acids (VFA), biogas production, and methane $\left(\%-\mathrm{CH}_{4}\right)$ content in produced biogas. The standard procedures were applied for total and soluble COD (TCOD and SCOD) (\#5220), total solids (TS) (\#2540), and volatile solids (VS) (\#2540) analysis [26] $\mathrm{pH}$ was measured by a $\mathrm{pH}$ meter (WTW model $\mathrm{pH}$ 7.11), while VFA and Alk determination followed the titration method [27]. The produced biogas was measured daily by a gas counter; a device employs the water replacement concept for wet gas measurement. Produced biogas composition was sampling for analysis daily before feeding the reactor by gas chromatography (GC) equipped with a thermal conductivity detector (Shimadzu, Japan; model 14B-Porapak-N column). The operation conditions were 70, 120 and $120^{\circ} \mathrm{C}$ for the oven, injector, and detector temperatures. Helium gas at $30 \mathrm{~mL} / \mathrm{min}$ was used as the carrier. The VFAs composition was analyzed occasionally at the end of each OLR using GC equipped with a flame ionization (FID) detector (Shimadzu, Japan; model-9A-Carbowax B-DA column). In practice, after the liquid sample was collected, it was filtrated through filter paper. Then, the filtrated solution was centrifuged at 10,000 rpm for $10 \mathrm{~min}$. The supernatant was acidified by oxalic acid at $0.1 \%$ (by volume) before analysis using GC-FID operated at 170,200 and $200^{\circ} \mathrm{C}$ for the oven, injector, and detector temperature conditions. Helium (50 $\mathrm{mL} / \mathrm{min}$ ) was used as the carrier and nitrogen $(50 \mathrm{~mL} / \mathrm{min})$ as a makeup gas. The VFAs composition focused on acetic acid (HAc), propionic acid ( $\mathrm{HPr})$, butyric acid $(\mathrm{HBu})$, and valeric acid (HVa) mainly.

\subsection{Microbial Characterization}

The development of microbial biomass and its activity in starter seed is essential to an anaerobic digester start-up. The methanogenic archaea's existing in WAS were verified using various application techniques: population number enumeration, methanogenic activity determination, methanogenic Arc identification, and morphological visualization. The number of archaea (Arc), mainly methane-producing bacteria (MPB), and the number of Eubacteria (EuB) in the initial inoculum were determined by the most probable number (MPN) method [28]. At the same time, an identification of MPB in WAS was conducted using molecular identification. The visualization observation by scanning electron microscopy (SEM) was implemented for the morphological characterization of raw WAS and biomass samples collected from AHR1 at the end of the experiment for both suspended and attached-bed one. Furthermore, a statistical analysis of ANOVA (one-way) using SPSS Statistics 17.0 was applied to the obtained results for significant meaning at 95\%-confidential ( $p<0.05$ ). The difference in average operational performance and stability by the influence of each inoculation was determined significantly.

\subsubsection{Specific methanogenic activity evaluation}

To evaluate microbial biomass's performance, herein, acetolactic methanogenic activity, an assay called specific methanogenic activity (SMA) [29] was applied. A batch experiment was performed for the initial inoculum and experimented biomass samples collected at the end of the experiment. SMA assay is an indirect measurement using to evaluate a microbe's performance in utilizing a specific substrate. The unit of SMA was expressed as g of substrate calculated in terms of COD per $g$ of biomass calculated as VS per day (g COD/g VS.d). In practice, anaerobic batch digestion was carried out in $125 \mathrm{ml}$ serum vials with a liquid working volume of 80-100 ml. These vials seeded with tested inoculum and feed with a specific substrate to target a group of microbes; acetate for MPB and glucose for non-MPB, at $0.1-0.5 \%$. About 0.1 to 0.3 of food to microbes $(\mathrm{F} / \mathrm{X})$ was applied. In each vial, the nutrient solution in the formula of Smolder et al. [30] was added after adjusted $\mathrm{pH}$ around 6.8-7.2. The vials were then flushed with a mixed gas of nitrogen and carbon dioxide (70:30), capped with butyl rubber stoppers and aluminium crimps. All tested bottles were mixed by hand twice daily and incubated at a controlled temperature $\left(37 \pm 1.0^{\circ} \mathrm{C}\right)$ incubator. The produced biogas and its composition were regularly monitored. Each tested condition was done in triplicate, and the controlled substrate and inoculum vials without substrate addition were also operated.

\subsubsection{Microbial population enumeration}

The number of eukaryotic bacteria $(\mathrm{EuB})$ and archaea (Arc) were enumerated using the most probable number (MPN) technique with five-fold serial dilution [28]. About 3-5 grams of samples 
were diluted in a phosphate buffer solution with one-nine fraction in the tube in practice. It was then mixed by vortex and sonication. The dilution $\left(10^{-5}-10^{-14}\right)$ of the stock sample were prepared, and the sample was then transferred into five tubes containing the selected culture media specifically different from enumerating EuB and Arc. The culture media was prepared accordingly to Zhang and Noike's formula [31] with some modifications. For $\mathrm{EuB}$, to easily monitor the operational change of reaction, phenol red was added as a $\mathrm{pH}$ indicating sign. The $\mathrm{pH}$ was reduced when acids were produced from the substrate digestion of microbes. The colour turned significantly from primarily red to yellow. While acetate at a concentration of $20 \mathrm{mM}$ was added to the medium of Arc cultivation. The tested tube was incubated and analyzed for 7-15 d, depending on the microbial group. To verify the positive condition, the tested tube that depicted a development growth sign by changing of colour or reducing of acetate, which verified by GC for EuB and Arc, respectively, was used as the criterion. The undeveloped tube was defined as a negative. An MPN table [28] was used to determine the number of $\mathrm{EuB}$ and MPB.

\subsubsection{Archaea identification}

To identify the existence of methanogenic Arc in WAS, a $16 \mathrm{~S}$ rDNA library was performed. The experiment divided into four steps, including 1) DNA extraction, 2) PCR amplification and clone library, 3) PCR-DGGE classification, and 4) DNA sequencing and analysis. The operation of each step was summarized. Step 1 DNA extraction: DNA extraction was based on Zhou et al. [32] using SDS with some modifications. Two replicated samples at $0.5 \mathrm{~g}$ (wet weight) of homogenized sludge was mixed with $700 \mathrm{~mL}$ of DNA extraction buffer (100 mM Tris-HCl, pH 8.0, $100 \mathrm{mM}$ sodium EDTA, pH 8.0, $100 \mathrm{mM}$ sodium phosphate, $\mathrm{pH}$ 8.0, $1.5 \mathrm{M} \mathrm{NaCl}$, $1 \% \mathrm{CTAB})$ and $50 \mu \mathrm{L}$ of lysozyme $(10 \mathrm{mg} / \mathrm{mL})$ in $2 \mathrm{~mL}$ of microcentrifuge tube with horizontal shaking at $200 \mathrm{rpm}, 37^{\circ} \mathrm{C}$ for $30 \mathrm{~min}$. After shaking, $100 \mathrm{~mL}$ of $20 \%$ SDS was added, the sample was then incubated at $70^{\circ} \mathrm{C}$ for $30 \mathrm{~min}$. After the centrifugation, the supernatant was collected and transferred into a new 2.0 $\mathrm{mL}$ microcentrifuge tube. The supernatants were combined and mixed with an equal volume of chloroform-isoamyl alcohol (24:1). The aqueous phase was recovered by centrifugation and precipitated by isopropanol at room temperature for $4 \mathrm{~h}$. The pellet of genomic DNA was obtained by centrifugation at $16,000 \times$ $\mathrm{g}$ for $20 \mathrm{~min}$ at $4^{\circ} \mathrm{C}$. It was washed with $70 \%$ of ethanol and re-suspended in sterile deionized water. Finally, genomic DNA was purified further using an extraction kit for Gel/PCR DNA fragments (Geneaid, Taiwan) as specified by the manufacturer. Step 2 PCR amplification and clone library: The nearly complete 16S rDNA of Arc was amplified using universal primers A20F [33] and U1492R [34]. The PCR conditions were (i) $5 \mathrm{~min}$ at $95^{\circ} \mathrm{C}$, (ii) 30 cycles of $30 \mathrm{~s}$ at $95^{\circ} \mathrm{C}, 30 \mathrm{~s}$ at $55^{\circ} \mathrm{C}$, and $2 \mathrm{~min}$ at $72^{\circ} \mathrm{C}$, and (iii) $7 \mathrm{~min}$ at $72^{\circ} \mathrm{C}$. Each amplicon of $16 \mathrm{~S}$ rDNA was ligated to pGEM-T easy vector and transformed into E.coli DH5 $\alpha$. Step 3 PCR-DGGE: PCR-DGGE was selected to provide an initial indication of genetic diversity. Practically, 16S rDNA clones of Arc libraries were extracted for plasmid using the alkaline lysis method. The specific primer for specific variable region V3-4 of Arc (344GC-F/522R) [35] was applied to increase the number of
DNA fragments. PCR products were then classed by Denaturing Gradient Gel Electrophoresis (DGGE) [36]. About 6.5\% of Acrylamide gel (40-55\% Denaturant gradients) in 0.5X TAE at 200V was operated for $5 \mathrm{~h}$ (C.B.S. DGGE model 2000 system, CA). Then, SYBR ${ }^{\circledR}$ Gold was applied for gel-colouring to visualize the DNA band's position under UV light conditions. Clones with the same band position on DGGE gel were grouped into so-called operation taxonomic units (OTUs). Step 4 DNA sequencing: The clone in each OTUs was then submitting to analysis for DNA sequencing, and the obtained results were compared to the database using a BLAST search in NCBI [37].

\subsubsection{Morphological visualization}

The morphological observation was conducted to visualize the microbes' characteristic in WAS, focusing on methanogens. The initial WAS sample was compared with the experimented biomass samples of AHR1 for the morphology visualizing by scanning electron microscopy (SEM). The initial WAS and biomass samples of the suspended and attached bed of AHR1 were collected. All samples were prepared and submitted for SEM analyses (JEOL/Oxford SEM model JSM-IT300) at the Scientific and Technological Research Equipment Center of Chulalongkorn University.

\section{Results and Discussion}

\subsection{Chemical and Biological Characteristics of Seed Inoculums}

Table 1 shows the chemical and biological characteristics of inoculums used in the study. Results depicted that the different inoculum source promoted different physical and chemical characteristics. PM, AN, and CD contained a relatively high VS/TS fraction for $73.5 \%, 81.8 \%$, and $85.0 \%$ compared to only $48.4 \%$ and $66.7 \%$ of WAS and CM. BOD of these inoculums varied for 0.03-0.24 g/g-wet sample. This organic composition of inoculum benefits in the prevention of inert accumulation inside the digester. The different inert fractions in the ash residue forms were promoted, and orderly was $41.6 \%, 33.2 \%, 26.5 \%, 18.2 \%$, and $14.9 \%$ for WAS, $\mathrm{CM}, \mathrm{PM}, \mathrm{AN}$, and CD. WAS contained relatively high ash content similar to CM, which naturally contained a high fixed solid fraction by adding some durable components such as sand or shell to its feed to stimulate stomach digestion. Moreover, WAS was a semi-solid material. This characteristic benefited to its transportation from origin to the start-up plant than the other source. In contrast to WAS, a low TS concentration found in AN, containing only 3.3\%-TS compared to $22.0-78.3 \%$-TS in manures. This diluted concentration of inoculum was considered as an adverse condition that promotes high transportation's expenditure.

It was noted that relatively high BOD and COD values were found for manures and WAS ranged between 0.12-0.67 g-COD/g-wet sample or 0.03-0.30 g-BOD/g-wet sample. This composition degraded quickly and was converted rapidly to acidic intermediate forms. The balance of acid utilizing and buffering capacity was then essential to control the system stability. Surprisingly, the WAS's methanogenic activity was similar to other sources, ranging between 0.10-0.21 g COD/g VS.d. High SMA performance found 
Table 1. Chemical and Biological Characteristics of Inoculums Used in the Study

\begin{tabular}{|c|c|c|c|c|c|}
\hline \multirow{2}{*}{ Parameters } & \multicolumn{5}{|c|}{ Source of inoculum } \\
\hline & WAS & PM & CD & $\mathbf{C M}$ & AN \\
\hline Chemical oxygen demand $(g / g)^{a}$ & 0.12 & 0.67 & 0.36 & 0.65 & 0.02 \\
\hline Biochemical oxygen demand (g/g wet) ${ }^{\mathrm{a}}$ & 0.03 & 0.30 & 0.30 & 0.24 & n.d. \\
\hline Total phosphate $(\mathrm{g} / \mathrm{g})^{\mathrm{a}}$ & 0.01 & 0.02 & 0.01 & 0.03 & n.d. \\
\hline Total Khejdahl nitrogen $(\mathrm{g} / \mathrm{g})^{\mathrm{a}}$ & 0.004 & 0.002 & 0.001 & 0.005 & n.d. \\
\hline Total solids $(\%)^{\mathrm{a}}$ & 18.9 & 52.4 & 22.0 & 78.3 & 3.3 \\
\hline Volatile solids $(\%)^{\mathrm{a}}$ & 9.1 & 38.6 & 18.7 & 52.0 & 2.7 \\
\hline VS/TS (\%) & 48.4 & 73.5 & 85.0 & 66.7 & 81.8 \\
\hline Ash $(\%)^{a}$ & 41.6 & 26.5 & 14.9 & 33.2 & 18.2 \\
\hline Moisture $(\%)^{\mathrm{a}}$ & 81.1 & 47.6 & 77.2 & 21.9 & 96.8 \\
\hline \multicolumn{6}{|l|}{ Number of microbes } \\
\hline Eukaryotic bacteria (MPN/g VS) & $1.5 \times 10^{12}$ & $2.1 \times 10^{13}$ & $2.4 \times 10^{9}$ & $7.0 \times 10^{13}$ & $4.3 \times 10^{7}$ \\
\hline Archaea (MPN/g VS) & $1.5 \times 10^{7}$ & $6.4 \times 10^{6}$ & $4.3 \times 10^{5}$ & $6.0 \times 10^{7}$ & $4.0 \times 10^{3}$ \\
\hline \multicolumn{6}{|l|}{ Microbial activities } \\
\hline SMA (g COD/g VS.d) & 0.12 & 0.15 & 0.21 & 0.10 & 0.19 \\
\hline Lag phase (d) & 1.0 & 0.2 & 0.0 & 0.3 & 0.0 \\
\hline $\mathrm{R}_{\mathrm{m}}(\mathrm{mL} / \mathrm{d})$ & 27.1 & 21.8 & 24.9 & 19.4 & 25.5 \\
\hline $\mathrm{CH}_{4}$ (\%-maximum concentration) & 56.8 & 64.3 & 67.4 & 58.4 & 68.9 \\
\hline Day to $60 \%$ of total gas production & 12.0 & 23.0 & 18.0 & 14.0 & 8.0 \\
\hline GUR (g/g VS.d) & 15.6 & 31.1 & 21.7 & 15.9 & 21.3 \\
\hline
\end{tabular}

${ }^{a}$ wet weight basis, n.d. not determine

for AN and CD, which were traditionally sourced and contained a surplus amount of MPB. These sources were originally being operated in an anaerobic condition. Another inoculum, such as CM and PM, also depicted significant active biomass activity promoting about 0.10-0.15 g COD/g VS.d. Similar findings were reported previously about $0.25-0.35$ g COD/g VS.d found in sludge biomass and manure, respectively [5]. It was reported that ruminal fluid was the most active biomass source for the start-up. From batch digestion of SMA assay, it was found that all inoculum adapted well with new digestion environments. There was no lag phase found for CD and AN, while about 3.6-24 hours was observed for WAS, PM, and CM. Methanogenic performances were developed soon after substrate injection. However, when looking at non-methanogenic microbial activity from the utilizing capacity of glucose (GUR), PM promoted the maximum GUR of about $31.1 \mathrm{~g} / \mathrm{g}$ VS.d compared to 15.6-21.7 g COD/g VS.d in the others. Rapid digestion of non-methanogenic microbes, active mainly in acidification, was previously concerned. During the start-up, balanced acidification in order to balance MPB and non-MPB's activities as desired. A stepwise increase of influent loading was suggested to maintain the system stability and balance the microbial activities between acid-producing and acid-utilizing bacteria [23, 38].

For the methanogenic population's number in each inoculum, a similar amount was found. The WAS contained Arc mainly MPB for $1.5 \times 10^{7} \mathrm{MPN} / \mathrm{g}$ VS compared to $6.4 \times 10^{6}, 4.3 \times 10^{5}, 6.0$ $\times 10^{7}$, and $4.0 \times 10^{3} \mathrm{MPN} / \mathrm{g}$ VS of CD, PM, CM, and AN, respectively. The maximum number of MPB was about $0.01 \%$ of the EuB, which ranged between $4.3 \times 10^{7}-7.0 \times 10^{13} \mathrm{MPN} / \mathrm{g}$ VS. Similar findings were reported by $\mathrm{Wu}$ et al. [19] and Williams and Brown, about $4.1 \times 10^{5}-1.5 \times 10^{8} \mathrm{MPN} / \mathrm{g}$ VS of methanogenic Arc found in sludge samples from an aeration unit [20]. It was worth noting that Arc in WAS was higher in number than PM, CD, and AN, but lower microbial activity promoted. The results of methanogenic revealed by molecular analysis are shown in Table 2 .

From Table 2, the Arc community as $16 \mathrm{~S}$ rDNA archaea library reveal found about 82 clones in WAS sample. These clones could be classed relatively into 16 OTUs. It was found that the populations were mainly in the phylum of Euryarchaeota, in which about $97.5 \%$ of total clones (80 clones) were methanogens. The primary orders were Methanomicrobials (7 OTUs), Methanosarcinales (8 OTUs), and Thermoplasmatales (1 OTU). Methanomicrobials was hydrogenotrophic that use hydrogen as the reducing agent in producing methane, while the other two clones, Methanosarcinales, and Thermoplasmatales were acetolactic methanogens converting acetate to methane. It was found that about $63.4 \%$ or 8 OTUs of identified clones was Methanosaeta. Whereas only 1 OTU each of the hydrogenotrophic methanogens in the genus of Methanoculleus and Methanospirillum was found. The results were similar to previous works. Acetoclastic methanogens had been reported as the dominant species of an archaeal community. Fredriksson et al. [39] reported that Mathanosaeta was the dominant Arc species in an activated sludge plant accounted for $1.6 \%$ of the total cell numbers in the sludge with single and colony forms of varied size. While Qin et al. [40] found that Methanosaeta-like microbes also dominated by Arc in sludge sample of the municipality's wastewater treatment plant. 
Table 2. Methanogenic Populations in Aerobic Sludge of the Domestic Treatment Plant

\begin{tabular}{|c|c|c|c|c|}
\hline Order & Clone & No. of clone (\%) & Similarity & Identity (\%) \\
\hline Methanomicrobials & & $28(34.1)$ & & \\
\hline genus Methanoculleus & WAS15 & $2(2.4)$ & Uncultured archaeon clone MH1100_A4C [11] & 96 \\
\hline genus Methanospirillum & WAS86 & $12(14.7)$ & Uncultured archaeon clone TANĀ5 [12] & 95 \\
\hline \multirow[t]{5}{*}{ genus Methanolinea } & WAS37 & $2(2.4)$ & Uncultured Methanomicrobiales archaeon clone QEEE1CB091 [13] & 96 \\
\hline & WAS53 & $2(2.4)$ & Uncultured Methanomicrobiales archaeon clone Pav-sed-205 & 97 \\
\hline & WAS66 & $4(4.9)$ & Toluene-degrading methanogenic consortium archaeon M 1 & 97 \\
\hline & WAS70 & $4(4.9)$ & Uncultured archaeon clone MTSArc_E4 & 99 \\
\hline & WAS97 & $2(2.4)$ & Uncultured archaeon clone MTSArc_E4 & 95 \\
\hline Methanosarcinales & & $52(63.4)$ & & \\
\hline \multirow[t]{8}{*}{ genus Methanosaeta } & WAS8 & $2(2.4)$ & Uncultured archaeon clone PS-Ar24 & 98 \\
\hline & WAS11 & $16(19.5)$ & Uncultured archaeon clone ACWCSP1C3 & 99 \\
\hline & WAS21 & $4(4.9)$ & Uncultured archaeon 61-2 & 96 \\
\hline & WAS30 & $2(2.4)$ & Uncultured archaeon clone PS-Ar24 & 100 \\
\hline & WAS39 & $14(17.1)$ & Uncultured archaeon clone PS-Ar14 & 100 \\
\hline & WAS54 & $4(4.9)$ & Uncultured Methanosarcinales archaeon clone QEEC1AF091 [13] & 99 \\
\hline & WAS58 & $2(2.4)$ & Uncultured archaeon clone MTSArc_E11 & 100 \\
\hline & WAS107 & $8(9.8)$ & Uncultured Methanosarcinales archaeon clone QEEC1BA061 [13] & 99 \\
\hline Thermoplasmatales & WAS17 & $2(2.4)$ & Uncultured archaeon clone MH1100_E4B [11] & 96 \\
\hline Total & & $82(100)$ & & \\
\hline
\end{tabular}

\subsection{Start-up Performance of AHRs}

During the start-up period, the performance of the digester was regularly monitored via operational parameters such as $\mathrm{pH}$, Alk, VFA, and biogas. The discussion mentioned organic loading capacity, COD removal efficiency, and gas productivity of different seed implements.

\subsubsection{OLR loading capacity}

The operational performance of AHRs inoculated differently by WAS and co-culture of WAS with the other inoculums is summarized in Fig. 1-3 and Table 3. The different start-up times to accomplish about $4.0 \mathrm{~kg} \mathrm{COD} / \mathrm{m}^{3} . \mathrm{d}$ were promoted in each reactor, taking about 1.5-3.3 months. In Fig. 1, an organic loading rate applied to each AHRs is showed. It was observed that the organic loading rate of AHR1-WAS and AHR2-WAS-PM was slow. It took almost 70-98 d or 2.5-3.3 months to achieve $4.0 \mathrm{~kg}$ COD $/ \mathrm{m}^{3} . \mathrm{d}$ compared to 1.5-1.7 month of AHR2, AHR3, and AHR5. The unbalance of acid production and utilization capacity was a crucial indicator in this time-consumed factor. In general, during the start-up period, the balance of acid production by non-methanogenic bacteria and acids utilization by methanogens is the key. In wastewater treatment, methanogen is typically limited due to the growth limit rate and affected the digester's overall capacity. This capacity compares the ability of microbial biomass per specific mass to grade incoming substrate, which varies not only by feeding but also by remaining or excess organic matter in biomass. Considering HRT, it corresponded well with the loading rate. The HRT was reduced relative to OLR increase from about $13 \mathrm{~d}$ to $4 \mathrm{~d}$ subsequently. The rapid reduction in HRT or an increase in OLR in AHR1 and AHR2 harmful to its stability. This reduction caused the VFAs to surge production and accumulation towards this initial period. A longer time was needed to maintain the previous loads and stability. This period was an adaptation required for microbial acclimatization and

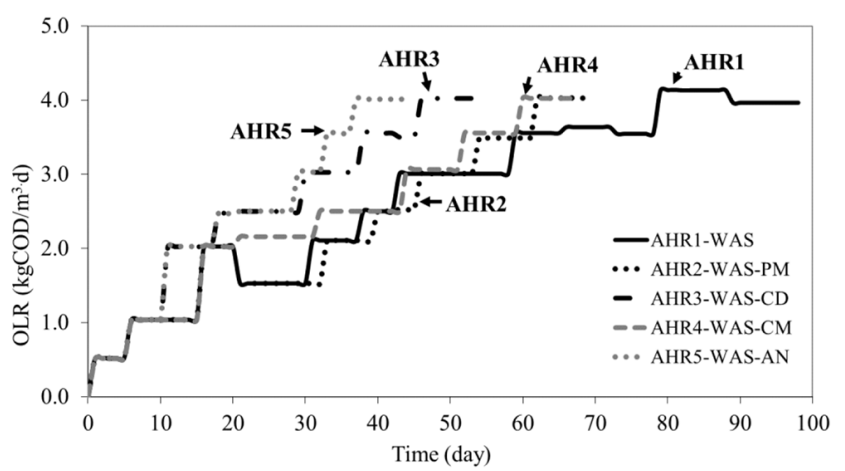

Fig. 1. Organic loading rate of AHRs inoculated differently by aerobic sludge.

increase population number to combat with the remaining substrate originally contained in WAS.

It was stated previously that WAS and manures contained high organic content. This remaining organic was an obstacle to feed a new substrate. After digestion was prolonged for 1-2 cycles, the delay in organic loading capacity was observed. AHR1-WAS performed a slightly lower organic loading rate. This unfavourable condition associated directly with an accumulation of VFA and a dropping of $\mathrm{pH}$, particularly on the 18th-25th of operation. The $\mathrm{pH}$ of AHR1 was reduced continuously from the initial values of 7.5 to 6.5 within $20 \mathrm{~d}$. Thus, the OLR of AHR1-WAS was intermittently reduced to maintain its stability. After a week of adaptation, the reactor could recover its previous stability and load. Similar to AHR1, AHR2-WAS-PM was instability promoted. A production of VFAs was rapidly and raised an accumulation of acidic intermediates initially for 1.9 to $2.5 \mathrm{~g} / \mathrm{L}$ in day 10th to day 20th. This rapid production of volatile fatty acids promoted acidic conditions that may be caused by the higher acid production activity of PM 
depicted as GUR for 31.1 g COD/g VS.d. Although the OLR of AHR1 and AHR2 was lower than the other at the same period, these reactors still demonstrated a satisfying performance in COD removal efficiency. A similar performance was found for other reactors. This finding was the same as previous works of Benabdallah et al. [23] and Kobayashi et al. [41]. They reported the importance of inoculum's quality for the start-up of anaerobic digester. Fig. 1 shows the performance of AHRs indicating by organic loading rate with time.

\subsubsection{COD removal efficiency}

The reduction of organic constituents in wastewater directly affects by anaerobic microbial performance in the digester [7]. Results showed that inoculum performance was correlated with the digester's performance, especially at the initial stage of start-up. The different removal efficiencies were found significantly $(\mathrm{p}<0.05)$. At OLR of $0.5-1.0 \mathrm{~kg} \mathrm{COD} / \mathrm{m}^{3}$.d, similar COD removal efficiency $\left(\mathrm{COD}_{\text {rem }}\right)$ were observed in almost all AHRs: $86.4-95.4 \%$ and 92.2-96.4\% for TCOD and SCOD, respectively. The performance corresponded to the remaining organic substance inside each inoculum itself, particularly WAS. AHR1 and AHR2 depicted a slightly low rate of removal performance. These removal efficiencies were increased subsequently even when the OLR increased. At OLR of $4.0 \mathrm{~kg} \mathrm{COD} / \mathrm{m}^{3} . \mathrm{d}$, the similar performance of COD removal efficiencies of $89.4-95.4 \%$ and $92.2-96.4 \%$ for TCOD and SCOD, respectively, were observed in all reactors. The effluent concentrations were about 1.0-2.5 g TCOD/L or 0.8-1.7 g SCOD/L. These results depicted that microbial performance in each AHR was appropriately developed with time and organic loaded. The previous results also stated similarly, the importance of seed inoculum development of UASB [19] and an anaerobic fixed film reactor [16] were related to time and inlet feed. It was worth noting that the effluent concentration of AHR1 was high initially by the remaining substrate of WAS. This substrate also promoted organic acids accumulation, which needed a longer time to acclimatize and utilize these intermediates, as stated previously. In Fig. 2, the COD concentration in the effluent of each AHR is shown.

In comparison, the increase of OLR was more rapid in AHR3-WAS-CD and AHR5-WAS-AN. The benefit of the MPB populations was positive in these digesters. The unfavourable condition

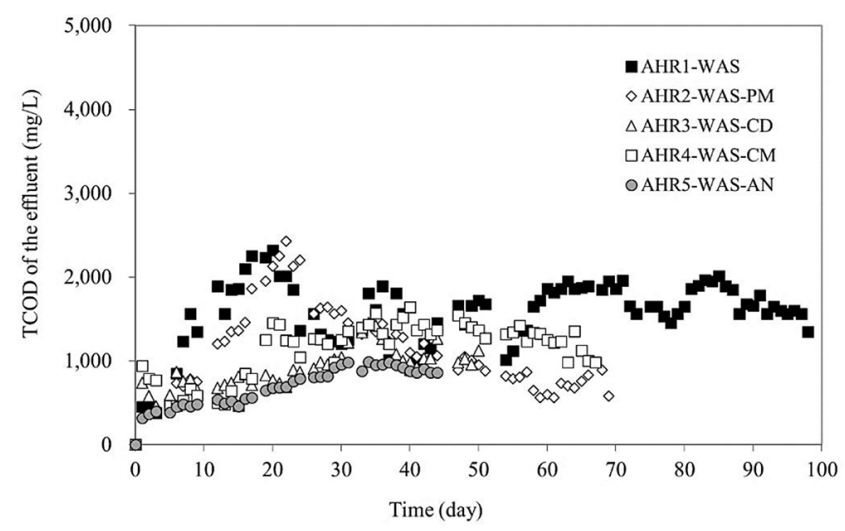

Fig. 2. Total COD in the effluent of AHRs inoculated differently by aerobic sludge. promoted by the non-methanogenic population's activity found contrastingly for co-inoculation with PM (AHR2-WAS-PM). The promotion of VFAs and their accumulation occurred. The balance of acid production and utilization was then vital to the stabilization of excess VFAs. The importance of the methanogenic population in seed inoculum on stabilizing the variation during start-up anaerobic digester had been studied previously. The development of microbes that could combat a high concentration of VFAs, mainly HAc, was also stated [38]. A large microbial community, particularly the methanogenic diversity in cow manure, had been reported. While the opposite conclusion was stated by Maroun and El-Fadel [41]. They noted that the anaerobic digester's start-up was possible without external seed inoculation instead of itself microbial composition. The microbial self-inoculation was also proposed by others elsewhere for sludge digesters [42]. However, the difficulty in maintaining the operating and controlling stability for correct digestion was observed.

\subsubsection{Gas production}

The gases production was differed from reactor to reactor depending on the inoculation, operational performance, and time of each reactor. However, at the end of the start-up period, about 6.3-9.6 $\mathrm{L} / \mathrm{d}$ of biogas was produced in each AHR. At an initial of 0.5-1.0 $\mathrm{kg} \mathrm{COD} / \mathrm{m}^{3} . \mathrm{d}$, the biogas production rate was low, ranged between 1.1-2.5 L/d for all reactors, but the difference in their methane content was observed. This variation was depending on organic load and inoculation differently. The produced biogas contained different and various compositions of methane for $21.9-38.0 \%$. Then, these daily gas productions increased with OLR increase. At OLR of $4.0 \mathrm{~kg} \mathrm{COD} / \mathrm{m}^{3} . \mathrm{d}$, the maximum gas production of about 6.3-9.6 $\mathrm{L} / \mathrm{d}$ was promoted. The methanogenic performance indicated as methane composition in produced biogas was increased relative to digestion time. A proper adaptation of microbes was observed significantly. Fig. 3 shows the biogas production and methane content of produced biogas in each digestion tank.

The methane productivity of each AHR differently varied by OLR and time. About 0.08-0.15 L-CH4/g COD $\mathrm{CH}_{4}$ was obtained at the initial stage. Then, these yields were increased and were stable

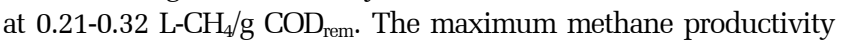
was orderly as AHR5, AHR3, AHR2, AHR4, and AHR1. A lower increase in gas production yield was observed in AHR1, corresponded with other performance indicators, i.e. $\mathrm{COD}_{\text {rem }}$ and loading rate. A similar finding was also found in the early stage of the start-up in many works. A specific substrate regulated this to the methanogenic population. It was noticeable that the co-inoculation of WAS and other inoculums favoured a stable and productive performance of methane production seen by methane content in the produced biogas, particularly AHR3, which inoculated by WAS and CD. The acceptable quality in the excellent background history of starter seed resulted in the rapid development of its methanogenic performance. The higher methane content was found for co-inoculation rather than mono sludge inoculation, particularly AHR4 and AHR5. This result was similar to Oz et al. [43], who concluded that the increase of inoculated seed's methanogenic population was empirical and indicated methane production activities during the start-up operation. This production was well agreed with famous characterization confirmed as an 

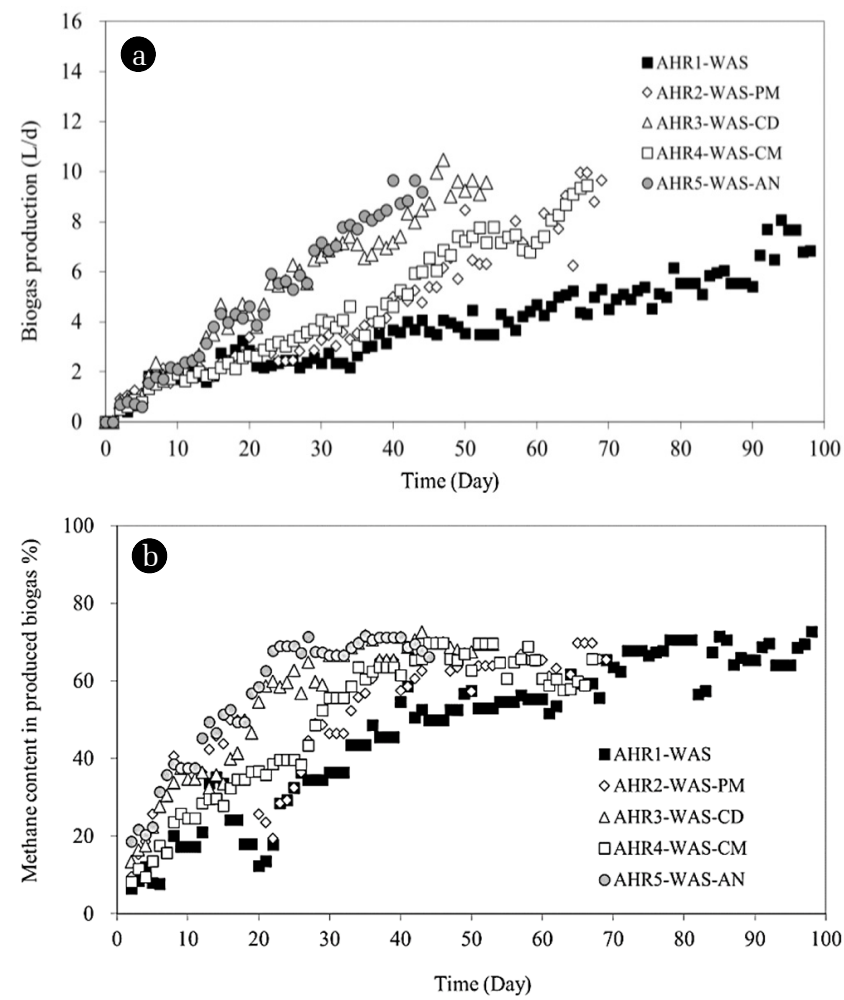

Fig. 3. (a) Biogas production and (b) methane content of AHRs with different inoculation.

intensive concentration and profitable production of MPB in ruminal manures. Moreover, the different loading capacity and time to complete the OLR of $4.0 \mathrm{~kg} \mathrm{COD} / \mathrm{m}^{3}$.d were promoted. It was found that almost two months was faster when inoculating with WAS and CD than WAS only. While the other manure depicted a similar performance and achieved about 25-35 d more quickly than AHR1. However, the long term operation performance and stability of each digester should be carefully considered. The ultimate loading capacity of each reactor was related closely to its initial start-up stage.

\subsection{Digester Stability}

A successful start-up in a short period and satisfied efficacy in long-term performance are expected in anaerobic digester operation. This stable performance relies on the balancing of microbial performance involved in anaerobic digestion schemes. In Fig. 4 and Table 3 , the digester's stabilities which regularly monitored, are shown. The results depicted that the different inoculation promoted different environmental condition, significantly for alkalinity ( $p$ $<0.05)$ inside each digester. The different stages of the start-up also encouraged different variations in the digester's stability. The $\mathrm{pH}$ of AHR1-WAS variated significantly in the range of 6.7-7.7, similarly to AHR2-WAS-PM for 6.6-7.2 and compared to 6.8-7.4 in the other reactor. These reductions of $\mathrm{pH}$ in AHR1 and AHR2 were continuously performed. This situation may result from the microbial populations and the community and the basic chemical properties of each inoculum. The balance of acidic intermediates

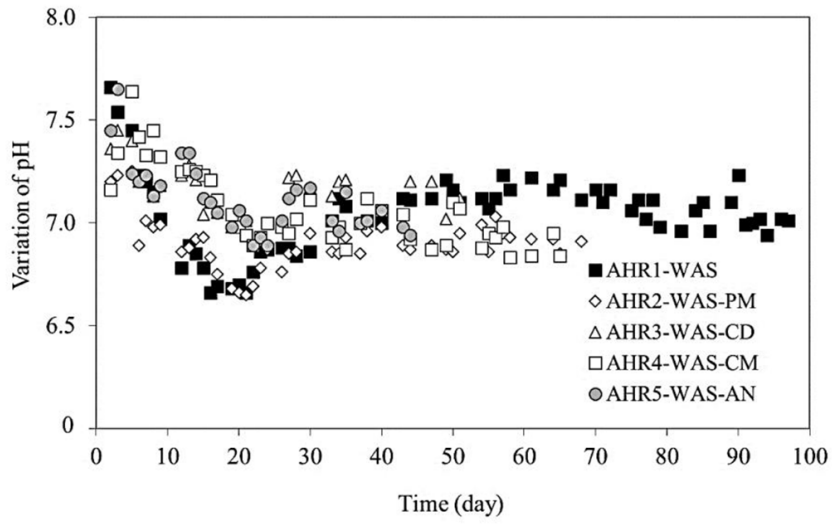

Fig. 4. Variations of $\mathrm{pH}$ in the effluent of AHRs.

produced by non-methanogens and methanogens' acid utilization rate played a key factor. At the first month of start-up, an accumulation of $\mathrm{HPr}$ and $\mathrm{HBu}$ of about $5.1-7.0 \%$ and $3.2-5.3 \%$ were observed in AHR1 and AHR3. This concentration was higher than the usual condition containing only 1.1-2.0\%. HAc was the main composition of VFAs in the effluent accounted for 50.6-70.8\%. In consequence, the VFAs accumulation trended to promote an unbalance condition in these reactors. Rapid production of acids was promoted in AHR3. While the effect of the remaining substrate of inoculated WAS was also found in AHR1. However, a better-balanced condition was maintained in AHR3, AHR4, and AHR5. In AHR3, the concentration of Alk was significantly $(p<0.05)$ higher than the other reactors ranging from $2.2-2.5 \mathrm{~g} / \mathrm{L}$. This characteristic is a fundamental condition of manure digestion that promotes an ammonium buffer condition usually. However, after maintaining their previous capacity, AHR1 and AHR3 could recover the usual stabilization and performance. Similar performance and stability were maintained.

\subsection{Microbial Biomass Development}

To determine microbial development after initial inoculation, biomass samples from the attached and the suspended growth zone of each AHR were harvested at the end (OLR of $4.0 \mathrm{~kg} \mathrm{COD} / \mathrm{m}^{3} . \mathrm{d}$ ) for SMA analysis compared to the initial inoculum. It was found that the attached biomass had developed differently on the nylon's surface. The growth was relative commonly with the organic loading and an increase from none at the initial stage to around 4.8-13.1 $\mathrm{g} \mathrm{VS} / \mathrm{m}^{2}$ at the end. AHR5 promoted the more rapid growth of attached biomass which was $13.1 \mathrm{~g} \mathrm{VS} / \mathrm{m}^{2}$. While about 4.8, 8.1, 9.9, and $9.6 \mathrm{~g} \mathrm{VS} / \mathrm{m}^{2}$ were found in AHR1, AHR2, AHR3, and AHR4, respectively. These analyses found that suspended microbes were significantly varied through their VS initially. At a stable stage of $4.0 \mathrm{~kg} \mathrm{COD} / \mathrm{m}^{3} . \mathrm{d}$, the suspended biomass was around 46.5-65.2 g VS. The amount and activity were a significant indicator of starting-up in the digester. It was found that SMA had increased significantly for the attached biomass, generally around 1.2-1.6 times or to be approximately 0.1-0.3 g COD/g VS.d; however, the reduction was promoted for the suspended biomass sample. The SMA was reduced by $11.2-24.5 \%$ (compared to the SMA of the initial inoculum). This acidic condition was a simple 

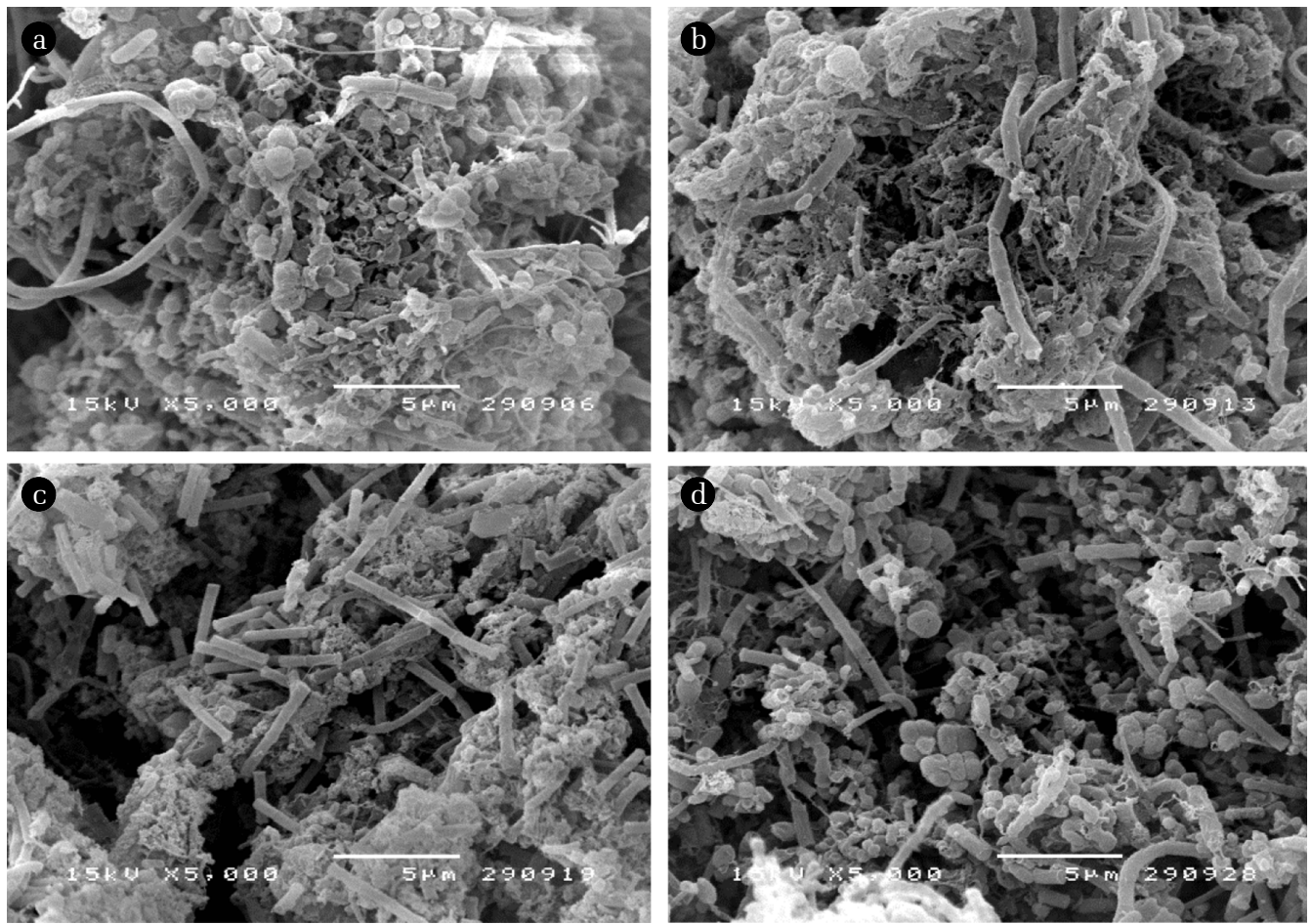

Fig. 5. Morphological characteristics of microbial biomass; (a)-(b) raw WAS, (c) the suspended sludge, and (d) attached biofilm of AHR1.

Table 3. Performance and Stability of AHRs Inoculated Differently by Aerobic Sludge

\begin{tabular}{|c|c|c|c|c|c|c|c|c|c|c|}
\hline $\begin{array}{c}\text { OLR } \\
\left(\mathrm{kg} / \mathrm{m}^{3} . \mathrm{d}\right)\end{array}$ & AHR & Inoculum & $\begin{array}{c}\mathrm{COD}_{\text {rem }}^{\mathrm{a}} \\
(\%)\end{array}$ & $\mathrm{pH}^{\mathrm{a}}$ & $\begin{array}{l}\mathrm{VFA}^{\mathrm{a}} \\
\left(\mathrm{g} / \mathrm{L}^{b}\right)\end{array}$ & $\begin{array}{l}\mathrm{ALK}^{\mathrm{a}} \\
\left(\mathrm{g} / \mathrm{L}^{c}\right)\end{array}$ & $\begin{array}{c}\text { Biogas }^{\mathrm{a}} \\
\text { (L/d) }\end{array}$ & $\begin{array}{c}\mathrm{CH}_{4}^{\mathrm{a}} \\
(\%)\end{array}$ & $\begin{array}{l}\text { Biogas yield }^{\text {a }} \\
\left(\mathrm{L} / \mathrm{COD}_{\text {rem }}\right)\end{array}$ & $\begin{array}{c}\mathrm{CH}_{4} \text { yield }^{\mathrm{a}} \\
\left(\mathrm{L} / \mathrm{g} \mathrm{COD}_{\mathrm{rem}}\right)\end{array}$ \\
\hline \multirow[t]{5}{*}{1.0} & 1 & WAS & $88.6 \pm 2.5$ & $6.9 \pm 0.1$ & $2.8 \pm 0.6$ & $1.9 \pm 0.1$ & $1.8 \pm 0.1$ & $21.9 \pm 9.2$ & 0.37 & 0.08 \\
\hline & 2 & WAS-PM & $92.6 \pm 2.3$ & $6.9 \pm 0.1$ & $2.9 \pm 0.0$ & $1.6 \pm 0.0$ & $2.0 \pm 0.2$ & $38.0 \pm 4.3$ & 0.39 & 0.15 \\
\hline & 3 & WAS-CD & $94.4 \pm 0.7$ & $7.2 \pm 0.0$ & $3.4 \pm 0.0$ & $2.3 \pm 0.2$ & $2.0 \pm 0.2$ & $32.9 \pm 3.8$ & 0.39 & 0.13 \\
\hline & 4 & WAS-CM & $96.1 \pm 0.6$ & $7.3 \pm 0.1$ & $0.5 \pm 0.1$ & $2.2 \pm 0.1$ & $1.7 \pm 0.2$ & $24.8 \pm 4.8$ & 0.33 & 0.08 \\
\hline & 5 & WAS-AN & $96.6 \pm 0.5$ & $7.2 \pm 0.0$ & $2.2 \pm 0.2$ & $2.1 \pm 0.1$ & $1.8 \pm 0.3$ & $36.2 \pm 2.8$ & 0.35 & 0.13 \\
\hline \multirow[t]{5}{*}{2.0} & 1 & WAS & $89.7 \pm 2.3$ & $7.1 \pm 0.1$ & $1.1 \pm 0.2$ & $2.0 \pm 0.1$ & $2.6 \pm 0.3$ & $42.6 \pm 4.5$ & 0.25 & 0.11 \\
\hline & 2 & WAS-PM & $90.8 \pm 0.5$ & $6.9 \pm 0.1$ & $0.9 \pm 0.1$ & $1.7 \pm 0.0$ & $3.4 \pm 0.3$ & $60.3 \pm 5.4$ & 0.36 & 0.22 \\
\hline & 3 & WAS-CD & $94.5 \pm 0.5$ & $7.2 \pm 0.1$ & $0.6 \pm 0.2$ & $2.3 \pm 0.1$ & $3.2 \pm 3.3$ & $36.3 \pm 3.9$ & 0.31 & 0.11 \\
\hline & 4 & WAS-CM & $91.7 \pm 1.4$ & $7.1 \pm 0.1$ & $1.0 \pm 0.2$ & $2.0 \pm 0.1$ & $3.0 \pm 0.6$ & $41.4 \pm 7.6$ & 0.3 & 0.13 \\
\hline & 5 & WAS-AN & $96.7 \pm 0.5$ & $7.2 \pm 0.1$ & $0.5 \pm 2.5$ & $2.0 \pm 0.1$ & $3.2 \pm 0.8$ & $47.5 \pm 1.0$ & 0.31 & 0.15 \\
\hline \multirow[t]{5}{*}{3.0} & 1 & WAS & $89.1 \pm 1.6$ & $7.1 \pm 0.1$ & $0.8 \pm 0.1$ & $2.1 \pm 0.1$ & $3.8 \pm 0.3$ & $53.5 \pm 2.4$ & 0.26 & 0.14 \\
\hline & 2 & WAS-PM & $92.8 \pm 0.5$ & $6.9 \pm 0.1$ & $0.8 \pm 0.1$ & $1.8 \pm 0.1$ & $6.4 \pm 0.9$ & $64.0 \pm 3.6$ & 0.42 & 0.26 \\
\hline & 3 & WAS-CD & $91.2 \pm 1.0$ & $7.1 \pm 0.1$ & $0.9 \pm 0.1$ & $2.5 \pm 0.2$ & $7.0 \pm 2.8$ & $68.2 \pm 3.8$ & 0.46 & 0.31 \\
\hline & 4 & WAS-CM & $89.6 \pm 0.7$ & $7.0 \pm 0.1$ & $1.2 \pm 0.2$ & $2.0 \pm 0.1$ & $6.8 \pm 0.6$ & $67.5 \pm 2.7$ & 0.46 & 0.31 \\
\hline & 5 & WAS-AN & $93.5 \pm 1.1$ & $7.1 \pm 0.1$ & $0.9 \pm 0.2$ & $2.0 \pm 0.1$ & $7.6 \pm 0.5$ & $68.9 \pm 2.2$ & 0.49 & 0.34 \\
\hline \multirow[t]{5}{*}{4.0} & 1 & WAS & $89.4 \pm 1.0$ & $7.0 \pm 0.1$ & $0.8 \pm 0.1$ & $2.2 \pm 0.2$ & $6.3 \pm 0.9$ & $66.9 \pm 4.4$ & 0.32 & 0.21 \\
\hline & 2 & WAS-PM & $95.4 \pm 0.3$ & $6.9 \pm 0.0$ & $0.9 \pm 0.0$ & $2.0 \pm 0.1$ & $8.9 \pm 1.3$ & $65.4 \pm 4.4$ & 0.41 & 0.27 \\
\hline & 3 & WAS-CD & $93.3 \pm 0.8$ & $7.1 \pm 0.1$ & $0.8 \pm 0.0$ & $2.4 \pm 0.1$ & $9.7 \pm 0.6$ & $67.6 \pm 2.6$ & 0.47 & 0.32 \\
\hline & 4 & WAS-CM & $92.9 \pm 0.9$ & $6.7 \pm 0.1$ & $1.1 \pm 0.1$ & $2.0 \pm 0.1$ & $8.4 \pm 1.9$ & $60.0 \pm 2.5$ & 0.41 & 0.25 \\
\hline & 5 & WAS-AN & $93.3 \pm 0.8$ & $7.1 \pm 0.1$ & $0.8 \pm 2.0$ & $2.0 \pm 0.1$ & $9.9 \pm 0.5$ & $68.7 \pm 1.1$ & 0.47 & 0.32 \\
\hline
\end{tabular}

${ }^{\mathrm{a}}$ average \pm standard deviation of data at the same OLR, ${ }^{\mathrm{b}}$ as HAc acetic acid. ${ }^{\mathrm{c}}$ as CaCO3

observation found in an acidification function of the suspended growth zone of AHR. An organic loading increase also promotes more organic acids concentration that influence, consequently, $\mathrm{pH}$ and acidic conditions. These experimental conditions favour a proper growth of the acid-producing population than methane-producing bacteria. 
To confirm the existence of MBP in WAS, a visualization using SEM was conducted only for the initial WAS and AHR1's samples which were considered as the based situation of the experiment. The suspended and attached biomass of AHR1 was collected for SEM compared to the initial sludge. Fig. 5 shows the microbial characterization of the biomass of raw WAS (a-b) and suspended (c) and attached biomass (d) samples. It was found that the diversified characteristics in such cocci, rod, curve rod, and filament bacteria were found for the initial sludge. The methanogenic like microbes were also found in raw WAS. Then, the lower diversified community was observed for the experimented biomass. In particular, the attached biomass, the Methanosarcina-like and Methanothrix-like microbes, were found. At the same time, similar profiles of WAS promoted in the suspended biomass.

In the discussion, the average performance of each AHRs is summarized in Table 3. It was found that the different inoculation promoted different start-up performances and stability, particularly at the initial period (OLR of $0.5-1.0 \mathrm{~kg} \mathrm{COD} / \mathrm{m}^{3}$.d). The different time used to achieve each OLR was observed. Mono sludge inoculation in AHR1 was able to start up the anaerobic digester. Although WAS contained a higher number of MPB, this population was low activity initially. Thus, AN with lower MPB depicted a rapid start-up than the other when co-inoculating with WAS. The quality of inoculum, in term of microbial SMA, was the most important criteria. However, after a long time operation required to accomplish the same OLR, good performance and stability were also promoted in AHR1-WAS. It was observed the different inoculation by WAS and its mixture with manures and $\mathrm{AN}$; the performance and stability were similarly promoted at the end of the start-up. A similar conclusion had been stated. The difference in microbial activity and community was a less significant factor for the start-up operation of the UASB reactor treating alcohol distillery wastewater [35]. The development of WAS microbes possibly occurred after prolonging the time for delay of loading capacity was promoted. For co-culture inoculation, AN and CD were two critical sources of inoculation to start-up digesters. The stable operational performance in each AHRs was observed. However, PM and $\mathrm{CM}$ also depicted a possibility in the further application, but less production and stable variation were observed. To apply these two sources as inoculum, the system stability and buffering capacity should be carefully monitored. The obtained results depict similarly to the previous works where the benefit of WAS in application to anaerobic digestion was confirmed. The different operational conditions in different applications seem to allow scope for different conditions and its strategy to achieve the operation's success, the same as the start-up of these AHRs.

\section{Conclusions}

The present study explored the ability of WAS to start up anaerobic hybrid reactors treating cassava wastewater. The different inoculation by WAS promoted operational performance, stability, and time-consumed differently. Co-inoculation of WAS and other inoculum sources, especially AN and CD, was an optimum strategy that engaged start-up rapidly. The mixed source of inoculum: WAS and AN in AHR5 and WAS and CD in AHR3 obtained more stability and rapid organic loading capacity. A shorter start-up period of about 1.0-1.8 months was achieved than other reactors. The balance of acid-producing and acid utilizing ability was a vital factor. For mono WAS inoculation, a gradual increase in organic loading paralleled with buffering capacity monitoring was suggested to avoid a rapid increase and accumulation of the acidic intermediates that harmful to the overall performance and stability of the digester. Microbial biomass was developed similarly in all digesters. This finding demonstrated the potent of WAS utilization as starter seed for an anaerobic digester start-up, which enables its practical implementation and operation economically.

\section{Acknowledgement}

This work supports by a grant from the National Research Council of Thailand (NRCT), Bangkok, Thailand.

\section{Author Contributions}

P.K. (Ph.D.) directed the research project, designed and conducted the experiments, analyzed the result, and wrote the manuscript. P.T. (B.Sc.) assisted in conducting the experiments and data preparation for analysis, N.B. (M. Sc.) conducted the molecular analysis. C.V.S (Ph.D.) assisted in manuscript preparation, discussion, and submission.

\section{References}

1. Verstraete W, Morgan-Sagastume F, Aiyuk S, Waweru M, Rabaey $\mathrm{K}$, Lissens $\mathrm{G}$. Anaerobic digestion as a core technology in sustainable management of organic matter. Water Sci. Technol. 2005;59:59-66.

2. Weiland P. Biogas production: current state and perspectives. Appl. Microbiol. Biotechnol. 2010;85(4):849-860.

3. Schnurer A. Biogas production: microbiology and technology. Anaerobes in biotechnology. 2016;195-234.

4. Gerardi MH. The microbiology of anaerobic digesters. John Wiley \& Sons. New Jersey. 2003.

5. Ozbayram EG, Ince O, Ince B, Harms H, Kleinsteuber S. Comparison of rumen and manure microbiomes and implications for the inoculation of anaerobic digesters. Microorganisms. 2018;6(1):15.

6. Yang J, Wang D, Luo Z, Zeng W. Anaerobic mono-digestion of pig manure in a leach bed coupled with a methanogenic reactor: effects of the filter media. J. Clean. Prod. 2019;234: 1094-1101.

7. Rajput AA, Sheikh Z. Effect of inoculum type and organic loading on biogas production of sunflower meal and wheat straw. Sustain. Environ. Res. 2019;29(1):1-10.

8. De Vrieze J, Raport L, Willems B, et al. Inoculum selection influences the biochemical methane potential of agro-industrial substrates. Microbial. Biotechnol. 2015;8(5):776-786.

9. Koch K, Lippert T, Drewes JE. The role of inoculum's origin on the methane yield of different substrates in biochemical 
methane potential (BMP) tests. Bioresour. Technol. 2017;243:457-463.

10. Mahdy A, Fotidis IA, Mancini E, Ballesteros M, GonzálezFernández C, Angelidaki I. Ammonia tolerant inocula provide a good base for anaerobic digestion of microalgae in third generation biogas process. Bioresour. Technol. 2017;225:272-278.

11. Suwannoppadol S, Ho G, Cord-Ruwisch R. Rapid start-up of thermophilic anaerobic digestion with the turf fraction of MSW as inoculum. Bioresour. Technol. 2011;102(17):7762-7767.

12. El-Fadel M, Saikaly P, Ghanimeh S. Startup and stability of thermophilic anaerobic digestion of OFMSW. Crit. Rev. Environ. Sci. Technol. 2013;43(24):2685-2721.

13. Mkruqulwa U, Okudoh V, Oyekola O. Optimizing methane production from co-digestion of cassava biomass and winery solid waste using response surface methodology. Waste Biomass Valorization. 2019;11:4799-4808.

14. Tanticharoen M, Bhumiratanatries S. Wastewater treatment in agro-industry: a case study in Thailand. In: Sastry CA, Hashim MA, Agamuthu P, editors. Waste treatment plants. John Wiley \& Sons (Asia). 1995.

15. Kullavanijaya P, Paepatung N, Laopitinun O, Noppharatana A, Chaiprasert P, Songkasiri W. An overview of status and potential of biomethanation technology in Thailand. KMUTT Res Dev. J. 2007;30(4):693-700.

16. Escudie R, Cresson R, Delgenes JP, Bernet N. Control of start-up and operation of anaerobic biofilm reactors: an overview of 15 years of research. Water Res. 2011;45(1):1-10.

17. Pasda N, Panichsakpatana S, Limtong P, Oliver R, Montange D. Evaluation of Bangkok sewage sludge for possible agricultural use. Waste Manag. Res. 2006;24:167-174.

18. Sreesai S, Peapueng P, Tippayamongkonkun T, Sthiannopkao S. Assessment of a potential agricultural application of Bangkok-digested sewage sludge and finished compost products. Waste Manage Res. 2013;31(9):925-936.

19. Wu WW, Hu J, Gu XX, Zhao YY, Zhang H, Gu G. Cultivation of anaerobic granular sludge in UASB reactors with aerobic activated sludge as seed. Water Res. 1987;21(7):789-799.

20. Williams D, Brown JW. Archaeal diversity in a municipal wastewater sludge. Atlas J. Biol. 2010;1(2):30-33.

21. Lens PN, De Poorter MP, Cronenberg CC, Verstraete WH. Sulfate reducing and methane producing bacteria in aerobic wastewater treatment systems. Water Res. 1995;29(3):871-880.

22. Kim M, Speece RE. Aerobic waste activated sludge (WAS) for start-up seed of mesophilic and thermophilic anaerobic digestion. Water Res. 2002;36:3860-3866.

23. Benabdallah EHT, Dosta J, Mata-Alvarez J. Start-up and HRT influence in thermophilic and mesophilic anaerobic digesters seeded with waste activated sludge. Chem. Biochem. Eng. Q. 2007;21(2):145-149.

24. Chaiprasert P, Suvajittanont W, Surarak B, Tanticharoen M, Bhumiratana S. Nylon fibers as supporting media in anaerobic hybrid reactors: it's effects on system's performance and microbial distribution. Water Res. 2003;7(19):4605-4612.

25. Nandy T, Kaul SN, Sekhar VSS. Waste management in the tapioca based starch industry. Int. J. Environ. Stud. 1995;48(2):81-96.

26. Anderson GK, Yang G. Determination of bicarbonate and total volatile acid concentration in anaerobic digesters using a simple titration. Water Environ. 1992;53:53-59.
27. APHA (American Public Health Association). Standard methods for examination of water and wastewater. 20th ed. Washington DC, USA. 1998.

28. Cochran WG. Estimation of bacterial densities by means of the most probable number. Biometrics. 1950;6:105-116.

29. Soto M, Mendez R, Lema JM. Methanogenic and non-methanogenic activity tests-theoretical basis and experimental set up. Water Res. 1993;27(8):1361-1376.

30. Smolders GJF, Van der Meij J, Van Loosdrecht MCM, Heijnen JJ. Model of the anaerobic metabolism of the biological phosphorus removal process: stoichiometry and $\mathrm{pH}$ influence. Biotechnol. Bioeng. 1994;43(6):461-470.

31. Zhang CT, Noike T. Comparison of one-phase and two-phase anaerobic digestion processes in characteristics of substrate degradation and bacterial population levels. Water Sci. Technol. 1991;23(7-9):1157-1166.

32. Zhou J, Bruns MA, Tiedje JM. DNA recovery from soils of diverse composition. Appl. Environ. Microbiol. 1996;62(2):316-322.

33. Orphan VJ, Taylor LT, Hafenbradl D, Delong EF. Culturedependent and culture-independent characterization of microbial assemblages associated with high temperature petroleum reservoirs. Appl. Environ. Microbiol. 2000;66:700-711.

34. Amann RI, Ludwig W, Schleifer KH. Phylogenetic identification and in situ detection of individual microbial cells without cultivation. Microbiol. Rev. 1995;59(1):143-169.

35. Akarsubasi AT, Ince O, Oz NA, Kurdar B, Ince BK. Evaluation of performance, acetoclastic methanogenic activity and archaeal composition of full-scale UASB reactors treating alcohol distillery wastewaters. Process Biochem. 2006;41(1):28-35.

36. Santegoeds CM, Damgaard LR, Hesselink G, et al. Distribution of sulfate-reducing and methanogenic bacteria in anaerobic aggregates determined by microsensor and molecular analyses. Appl. Environ. Microbiol. 1999;65(10):4618-4629.

37. Altschul SF, Gish W, Miller W, Myers EW, Lipman DJ. Basic local alignment search tool. J. Mol. Biol. 1990;215(3):403-410.

38. Lins P, Reitschuler C, Illmer P. Development and evaluation of inocula combating high acetate concentrations during the start-up of an anaerobic digestion. Bioresour. Technol. 2012;110:167-173.

39. Fredriksson N J, Hermansson M, Wilen B M. Diversity and dynamics of Archaea in an activated sludge wastewater treatment plant. BMC microbiology. 2012;12.1:1-18.

40. Qin H, Ji B, Zhang S, Kong Z. Study on the bacterial and archaeal community structure and diversity of activated sludge from three wastewater treatment plants. Mar. Pollut. Bull. 2018;135: 801-807.

41. Maroun R, El Fadel M. Start-up of anaerobic digestion of source-sorted organic municipal solid waste in the absence of classical inocula. Environ. Sci. Technol. 2007;41(19):6808-6814.

42. Kobayashi T, Yasuda D, Li YY, Kubota K, Harada H, Yu HQ. Characterization of start-up performance and archaea community shift during anaerobic self-degradation of waste activated sludge. Bioresour. Technol. 2009;100:4981-4988.

43. Oz NA, Ince O, Turker G, Ince BK. Effect of seed sludge microbial community and activity on the performance of anaerobic reactors during the start-up period. World J. Microbiol. Biotechnol. 2012;28(2):637-664. 